\title{
Active acoustic examination of the diving behavior of murres foraging on patchy prey
}

\author{
Kelly J. Benoit-Bird ${ }^{1, *}$, Kathy Kuletz ${ }^{2}$, Scott Heppell ${ }^{3}$, Nathan Jones ${ }^{4}$, Brian Hoover ${ }^{4}$ \\ ${ }^{1}$ College of Oceanic and Atmospheric Sciences, Oregon State University, 104 COAS Administration Building, Corvallis, \\ Oregon 97331, USA \\ ${ }^{2}$ US Fish and Wildlife Service, 1011 E. Tudor Road, Anchorage, Alaska 99503, USA \\ ${ }^{3}$ Department of Fisheries and Wildlife, Oregon State University, 104 Nash Hall, Corvallis, Oregon 97331, USA \\ ${ }^{4}$ Moss Landing Marine Laboratories, 8272 Moss Landing Road, Moss Landing, California 95039, USA
}

\begin{abstract}
During the 2008 and 2009 breeding seasons of murres Uria spp., we combined visual observations of these predators with active acoustics (sonar), fish trawls, zooplankton net tows, and hydrographic measurements in the area surrounding breeding colonies in the southeastern Bering Sea. We acoustically detected thousands of bubble trails that were strongly correlated with the number of visually detected murres, providing a new tool for quantitatively studying the foraging ecology of diving birds. At the regional scale, the number of acoustically detected bubble trails, which served as a proxy for diving murre abundance, was related to the combined availability and vertical accessibility of squid, krill, and pollock. There were, however, no clear relationships at this scale between diving murres and any individual prey taxon, highlighting the importance of prey diversity to these animals. Individual krill patches targeted by murres had higher krill density and were located shallower than the mean depth of krill patches, but were similar in total krill abundance and overall size. The diving depth of murres within krill patches was highly correlated to the depth of the upper edge of these patches, whereas murres found outside of krill patches showed a depth distribution similar to that of juvenile pollock. Throughout the study area, murres showed strong diel patterns in their diving behavior in response to the diel migrations of their prey. These results suggest that murres select prey with specific patch characteristics implying effective information gathering about prey by murres. The high proportion of diving murres in aggregations and their consistent inter-individual spacing support the hypothesis that intraspecific local enhancement may facilitate foraging in these predators.
\end{abstract}

KEY WORDS: Foraging $\cdot$ Seabirds $\cdot$ Predator-prey $\cdot$ Acoustics

Resale or republication not permitted without written consent of the publisher

\section{INTRODUCTION}

Spatial heterogeneity, or patchiness, of physical characteristics and organisms is a general phenomenon in the ocean (Steele 1978). The distribution of prey has a strong effect on the energetic gains and costs of foraging (Tiselius et al. 1993), foraging success, and overall predator performance (Boyd 1996). To be successful, a predator must track changing prey patterns and respond to complex heterogeneity at different spatial and temporal scales (Russell et al. 1992, Mason \& Brandt 1996). However, documentation of strong spatial association between marine predators and their prey at small scales (e.g. 10s to 100s of meters) is uncommon (see review by Rose \& Leggett 1990). Spatial concordance of marine birds and their prey, for example, is largely lacking at small scales when not associated with strong physical features (reviewed in Hunt 1990, Hunt et al. 1999, Swartzman \& Hunt 2000). 
Murres Uria spp., members of the alcid family, are pursuit-diving marine birds that feed on a variety of fish and zooplankton and other invertebrate prey (Gaston \& Jones 1998) at depths up to $200 \mathrm{~m}$ (Croll et al. 1992, Takahashi et al. 2008). Previous work has shown that murres can switch their diet according to foraging location (Decker \& Hunt 1996, Kokubun et al. 2008) and environmental conditions (Decker et al. 1995, Takahashi et al. 2008). Prey variability during the breeding season in the summer months can affect the reproductive performance of murres (Ainley et al. 1995, Decker et al. 1995), indicating the importance of accessible prey to these populations. During breeding, adult murres function as central-place foragers whose foraging time and distance are constrained by the need to repeatedly return to the nesting colony (Benvenuti et al. 1998, Gaston \& Jones 1998). Murres typically provision their chicks with a single prey item that they deliver to the breeding site in the bill (Gaston \& Jones 1998), providing their chicks with highly variable diets typically comprised of a variety of fish and cephalopod species (Decker et al. 1995, Sinclair et al. 2008).

The Pribilof Islands in the southeastern Bering Sea provide nesting habitat for one of the largest concentrations of seabirds in the North Pacific (Hickey \& Craighead 1977). At various times, the prey of murres nesting in the Pribilof Islands has been found to be dominated either by krill (family Euphausiidae; Hickey \& Craighead 1977) or fish, primarily juvenile walleye pollock Theragra chalcogramma and lanternfish in the family Myctophidae (Swartzman \& Hunt 2000, Byrd et al. 2008). During our study period, coordinated field sampling efforts showed that adult murres had highly variable diets that included, in roughly the rank order of frequency of occurrence: krill, juvenile pollock, amphipods, squid, and a variety of other fish (N. Jones et al. unpubl. data). Murre chicks, in contrast, were provisioned with individual fish and squid and not the large zooplankton that made up a significant part of the adults' diets (V. Byrd, D. Irons, H. Renner and D. Roby pers. comm.).

The goal of the present work was to examine the consequences of spatial (patchiness) and short-term temporal (diel) variation in prey distribution on the at-sea distribution of foraging murres around the Pribilof Islands during the breeding season. The large variety of prey that murres consumed during the study and their ability to switch between one diet for themselves and another for their chicks suggests that to accomplish this, a wide variety of prey types must be quantified, in contrast to most previous seabirdprey studies which have focused on a single prey group (e.g. fish or krill; sensu Ainley et al. 1993, Veit et al. 1993, Zamon et al. 1996, Swartzman \& Hunt 2000, Davoren et al. 2003, Grünbaum \& Veit 2003, but see Kokubun et al. 2008). The diving capabilities of foraging murres indicate that the vertical overlap of murres and their prey must also be considered. Work on diving birds using depth-recording tags has shown seabird overlap with prey is indeed depthdependent (Zamon et al. 1996, Takahashi et al. 2008); however, most techniques used in field efforts have not allowed examination of this overlap (Obst 1985, Schneider \& Piatt 1986, Piatt 1990, Veit 1999) and many explicitly average prey abundance over large depth ranges (e.g. Grünbaum \& Veit 2003), ignoring the vertical patchiness that is likely critical to the foraging success of these air-breathing predators (Hunt et al. 1990). To provide information on the vertical overlap between murres and a variety of their prey across the entire day-night cycle, we employed multi-frequency active acoustic techniques to observe the horizontal and vertical distributions of diving murres and their prey simultaneously. Fisheries acoustic techniques have often been used to characterize the prey field of marine birds. However, acoustic prey data are typically paired with tracks of electronically tagged birds (Zamon et al. 1996, Wood et al. 2000, Takahashi et al. 2008), which limits sample sizes and makes the collection of concomitant prey data difficult, except at the broadest scales (Croxall et al. 1985), or with surface observations of the birds (e.g. Obst 1985, Schneider \& Piatt 1986, Piatt 1990, Veit 1999), which are limited to daylight hours and are not truly synoptic. Previous work on other marine predator-prey interactions has shown that the availability of synoptic data - data taken at the same temporal and spatial scales, with the same resolution and coverage-affect the interpretation of marine predator-prey overlap, increasing the strength of small-scale relationships (Rose \& Leggett 1990, Benoit-Bird \& Au 2003). Using the combined strengths of this approach, we sought to understand the decision-making rules murres use when foraging and why murres switch between prey groups across space and throughout the day.

\section{MATERIALS AND METHODS}

\section{Survey design}

In 2008, data were collected from mid-July to midAugust within $200 \mathrm{~km}$ of the Pribilof Islands centered at $57^{\circ} \mathrm{N}, 170^{\circ} \mathrm{W}$. In 2009 , sampling was conducted 
during the same time period but expanded to also include the adjacent $200 \mathrm{~km}$ north-northwest of Bogoslof Island in the Aleutian archipelago, where an additional murre nesting colony is located. During both years, sampling was conducted from chartered commercial fishing vessels and consisted of a series of $10 \mathrm{~km}$ long transects which were stratified among 3 hydrographically distinct zones (Coachman 1986): middle shelf with bottom depths $<100 \mathrm{~m}$, outer shelf with bottom depths between 100 and $200 \mathrm{~m}$, and slope with depths $>200 \mathrm{~m}$. A CTD (conductivity, temperature, depth) profile was conducted at the beginning and end of each transect, along with a single, depth-targeted net trawl for nekton and macro-zooplankton. Acoustic and visual sampling was conducted at a vessel speed of $9.3 \mathrm{~km} \mathrm{~h}^{-1}$ (5 knots) along the entire transect length and also during the transits between transects at vessel speeds between 11.1 and $14.8 \mathrm{~km} \mathrm{~h}^{-1}$ (6 to 8 knots) whenever conditions allowed.

During 2008, sampling was conducted from the $43 \mathrm{~m} \mathrm{FV}$ 'Frosti' and covered 20 transects that were randomly located and oriented within each zone (total $\mathrm{N}=60$ ) so that no transects were allowed to overlap or cross region boundaries. In addition, 50 transects were adaptively added during sampling in response to in situ observations and the behavior of tagged birds and marine mammals in a partner study, for a total of 110 transects sampled. Adaptive transects were spread over the sampling zones, times of day, and throughout the duration of the research cruise.

In 2009, sampling was conducted simultaneously from the FV 'Frosti' and the $32 \mathrm{~m} \mathrm{FV} \mathrm{'Gold} \mathrm{Rush'.} \mathrm{The}$ same randomly selected transects from 2008 in the area around the Pribilof Islands were sampled in 2009. To compensate for the increased sampling area, an additional 15 random transects were added in the outer shelf and 35 in the slope zones. Thirtyone adaptive transects were added throughout the study area in response to both in situ observations and information from collaborating animal tagging teams.

\section{Sampling}

Visual surveys were conducted by a single observer $6 \mathrm{~m}$ above the waterline from the starboard side of the vessel's wheelhouse, and employed a strip transect technique consistent with historic surveys in the North Pacific and the Bering Sea (Tasker et al. 1984, Decker \& Hunt 1996, Kitaysky et al. 2000).
Hand-held $10 \times 42$ binoculars were used during daylight hours to scan a $300 \mathrm{~m}$ arc, extending $90^{\circ}$ from the bow to the starboard beam, while the vessel was underway at speeds of $>9.3 \mathrm{~km} \mathrm{~h}^{-1}$. Bird behavior (flying, on the water, foraging) was noted for all birds within 3 distance bins at 0 to 100, 101 to 200, and 201 to $300 \mathrm{~m}$ from the vessel. Distances were calibrated using a combination of geometric and laser handheld rangefinders. Birds were identified to species whenever possible, and grouped by genus when necessary. All birds on the water were counted, and observations were entered directly into a laptop computer using the DLOG program (Ford Ecological Consultants) with a GPS interface to the ship's system. Ship location data were automatically recorded at $20 \mathrm{~s}$ intervals. Only birds on the water or foraging within $100 \mathrm{~m}$ of the vessel were used for the analyses presented here.

A 4-frequency echosounder system (Simrad EK60 at $38,70,120$, and $200 \mathrm{kHz}$ ) was used to provide nearly continuous information on a wide size range of meso-zooplankton and fish. Split-beam transducers were mounted $1 \mathrm{~m}$ below the surface on a rigid mount on the vessel's port side. The centers of each echosounder transducer were no more than $35 \mathrm{~cm}$ apart to maximize spatial comparability of the data. All echosounders used a $512 \mu$ s long outgoing pulse with a pulse repetition rate of approximately 2 to $3 \mathrm{~Hz}$. The $38 \mathrm{kHz}$ echosounder has a $12^{\circ}$ conical beam, while the 70,120, and $200 \mathrm{kHz}$ echosounders each have a $7^{\circ}$ conical beam. The echosounder system was calibrated with the settings and physical set up used for data collection just prior to sampling; this was done utilizing an indirect procedure that incorporated a $38.1 \mathrm{~mm}$ diameter tungsten carbide reference sphere as prescribed by Foote et al. (1987).

To ground-truth acoustic sampling, a $20 \mathrm{~min}$ net tow for fish and euphausiids was performed at a speed of 3 to $5 \mathrm{~km} \mathrm{~h}^{-1}$ starting at the beginning of each $10 \mathrm{~km}$ long transect, using an $8 \times 8 \mathrm{~m}$ opening Marinovich midwater trawl fitted with a $3 \mathrm{~mm}$ codend mesh liner. The depth of each trawl was targeted to sample depths of high acoustic scattering and was guided by a real time depth sensor to a maximum depth of $100 \mathrm{~m}$. The vertical and horizontal spread of the net were periodically measured with similar remote sensors. Contents of each trawl were identified and enumerated at sea, and a subsample of each identified species was measured for length.

At the beginning and end of each transect, a CTD profile was conducted to a depth of $100 \mathrm{~m}$ or to within $5 \mathrm{~m}$ of the seafloor in shallower waters using a SeaBird 19plus CTD guided by a real time remote 
pressure sensor (Simrad PI60). Each CTD was also equipped with a dissolved oxygen sensor (SBE 43), a transmissometer within the visible spectrum for most fish (WetLabs $530 \mathrm{~nm}$ [green] C-Star with a $25 \mathrm{~cm}$ pathlength), and a fluorometer (WetLabs ECOFLNTU or WetStar). Data from each profile were lowpass filtered, aligned to account for instrument lags, and edited for loops before calibrations were applied to convert data into appropriate measures. The fluorometers were calibrated during each year by comparing fluorometer readings to laboratory measurements of fluorescence from water samples collected simultaneously $1 \mathrm{~m}$ below the surface throughout the study area. Laboratory analysis followed standard protocols. Briefly, each sample was filtered immediately after collection onto a Whatman glass-fiber filter and frozen for chemical analysis. Pigments were then extracted in acetone, centrifuged, and analyzed using a Turner fluorometer. Calibration of each fluorometer in each year showed a strong, linear relationship between voltage readings of the in situ fluorometer and the quantitative samples. These relationships were used to convert raw voltages to chlorophyll a fluorescence values. From each profile, the total integrated chlorophyll, the chlorophyll maximum, and the depth of the chlorophyll maximum were quantified. In addition, a number of variables to describe the physical habitat were extracted from each profile, including the sea-surface temperature, thermocline depth (defined as the depth of the maximum rate of change in temperature), and water-column-averaged stratification (defined as the change in potential density over the change in depth $\left[\mathrm{d} \sigma_{\mathrm{t}} / \mathrm{d} z\right]$ from the surface to the bottom of the profile).

\section{Acoustic data analysis}

Volume scattering data starting at $5 \mathrm{~m}$ below the surface to $0.5 \mathrm{~m}$ from the sounder-detected bottom (shallow water) or to $200 \mathrm{~m}$ (deep water) were averaged over $5 \mathrm{~m}$ vertically by 5 pings horizontally. This provides enough data points to be averaged for appropriate interpretation of volume backscattering strength data, while still permitting patches $5 \mathrm{~m}$ or larger in vertical and horizontal extent to be classified. Volume backscattering strength $\left(S_{\mathrm{v}}\right)$ at $38 \mathrm{kHz}$ was then subtracted from that at $120 \mathrm{kHz}$ to separate data into 2 acoustic categories, one attributed to fish with swimbladders and one to euphausiids, based on the observed frequency response (Kang et al. 2002, Korneliussen \& Ona 2002). Cells with a $S_{\mathrm{v}} 120-S_{\mathrm{v}} 38$ in the range of -9.3 to $9.3 \mathrm{~dB}$ re $1 \mathrm{~m}^{-1}$ were assigned to the fish category, and those in the range of 9.3 to $30 \mathrm{~dB}$ re $1 \mathrm{~m}^{-1}$ were assigned to the euphausiid category (De Robertis 2010; confirmed by observations of monospecific aggregations in the present study). Using these classifications, all data not matching the 'fish' characteristics were masked out in the raw $38 \mathrm{kHz}$ echogram, and all data not matching the 'euphausiid' characteristics were masked out in the raw $120 \mathrm{kHz}$ echogram for additional prey analysis. As most murre foraging dives are $>10 \mathrm{~m}$ (Croll et al. 1992, Takahashi et al. 2008), the removal of the upper $5 \mathrm{~m}$ of acoustic data should have a limited effect on our ability to determine prey features important for murre foraging.

For transect-level analyses, backscatter not attributed to 'fish' was masked from the raw data so that backscatter in the 'fish' category could be integrated over the entire transect to a depth of $150 \mathrm{~m}$ at $38 \mathrm{kHz}$ using a $-85 \mathrm{~dB}$ re $1 \mathrm{~m}^{-1} S_{\mathrm{v}}$ integration threshold. Scattering in the 'euphausiid' category was similarly masked and integrated to $150 \mathrm{~m}$, a depth that encompasses $99 \%$ of the dives observed in tagged thickbilled murres (Croll et al. 1992), over the entire transect at $120 \mathrm{kHz}$ using a $-85 \mathrm{~dB}$ re $1 \mathrm{~m}^{-1} S_{\mathrm{v}}$ integration threshold. The signal to noise ratio (De Robertis \& Higginbottom 2007) of all data above $200 \mathrm{~m}$ was determined to be greater than the integration threshold, and so no background noise removal techniques were employed. The area scattering (NASC, nautical area scattering coefficient in $\mathrm{m}^{2}$ nautical mile $^{-2}$ ), a linear measure of integrated backscatter, along the entire transect for these data sets can be interpreted as an index for the total abundance of fish and krill, because the length-frequency distribution of each group was similar across samples.

For the analysis of individual patches of krill, sections of transects identified as 'euphausiids', as determined by the volume scattering difference approach, were further analyzed using Myriax's Echoview software (school detection module) on the masked, full-resolution $120 \mathrm{kHz}$ echograms. Data from the $120 \mathrm{kHz}$ echosounder were thresholded at a value of $-75 \mathrm{~dB}$ re $1 \mathrm{~m}^{-1}$, and then patches were defined as areas with returns above this threshold value that were contiguous over at least $2 \mathrm{~m}$ vertically and $10 \mathrm{~m}$ along the vessel's track (Barange 1994), after correcting for beam effects (Diner 2001). This allowed the detection of small, closely spaced individual patches by effectively disabling the option provided by the software to group small, closely spaced patches together into larger patches by setting candidate length and height equal to school length $(10 \mathrm{~m})$ and height $(2 \mathrm{~m})$ and the maximum linking 
distances to $1 \mathrm{~m}$. Data at $120 \mathrm{kHz}$ within the identified boundaries of the patch were then thresholded at a value of $-85 \mathrm{~dB}$ re $1 \mathrm{~m}^{-1}$ before the data were integrated over the patch area to provide mean volume backscattering. Echo energy integration (MacLennan \& Simmonds 1992) was then conducted on each patch using the mean standard length of individual euphausiids from the net tow along the same transect to calculate euphausiid mean target strength (Greene et al. 1991). For each patch, the mean volume scattering strength, total area scattering mean and maximum numerical density of euphausiids, mean patch depth, minimum patch depth, maximum patch depth, patch area, mean patch vertical extent, and mean patch horizontal extent were calculated.

A large number $(\mathrm{N}=5140)$ of distinctive, vertical echo trails were identified in the acoustic data (Fig. 1). These echoes had a strong (e.g. >10 dB re $1 \mathrm{~m}^{-1}$ ) frequency dependence with substantially higher scattering at $38 \mathrm{kHz}$ than at the other 3 frequencies (Fig. 2). The observed frequency response distribution can be accounted for by 4.7 to $10.8 \mathrm{~mm}$ diameter free bubbles (Urick 1983). These trails were typically observed from a few meters below the surface to depths $>10 \mathrm{~m}$. At the bottom edge of each trail, there was a single target with a higher target strength but similar frequency response. The depth of each of these strong single-target echoes, that is, large individual scatters at densities $\leq 1$ per sampling volume, were used to define the maximum observed depth of the target creating the trail. Single targets were detected between depths of 12 and $111 \mathrm{~m}$, which equates to a range of beam diameters of approximately 1.5 to $13.5 \mathrm{~m}$ and individual sampling volumes of 0.17 to $14.4 \mathrm{~m}^{3}$. For transect-level analysis, the number of trails per transect was calculated. Because each individual trail was observed over a wide range of depths, suggesting that they could be observed outside of the main lobe of the acoustic beam, differences in sampling volume with depth due to the beam pattern were not accounted for in these counts.

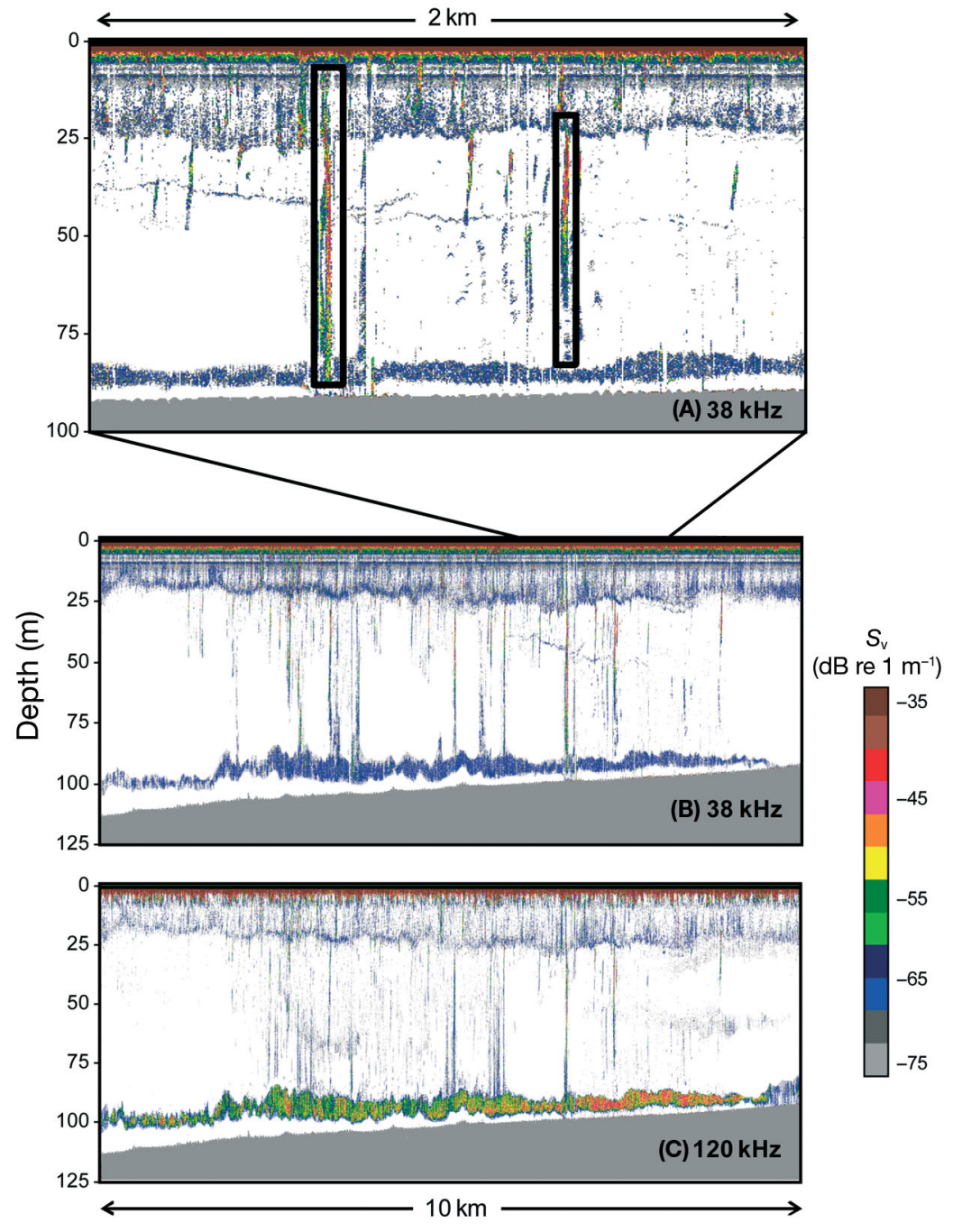

Fig. 1. Example echogram showing the unique trails found throughout the study area. $(\mathrm{B}, \mathrm{C})$ Full length of a planned transect at 2 different frequencies. In $(C)$, an acoustic scattering layer is apparent that is substantially stronger than at the lower frequency shown in (B). This indicates that the layer is comprised of krill, which was confirmed with a trawl sample. Strong, vertical streaks moving from near the surface to the krill layer are visible throughout the echogram and are most intense at $38 \mathrm{kHz}$ (B). (A) Enlargement of a section of (B), showing trails in greater detail with 2 paths highlighted by boxes 


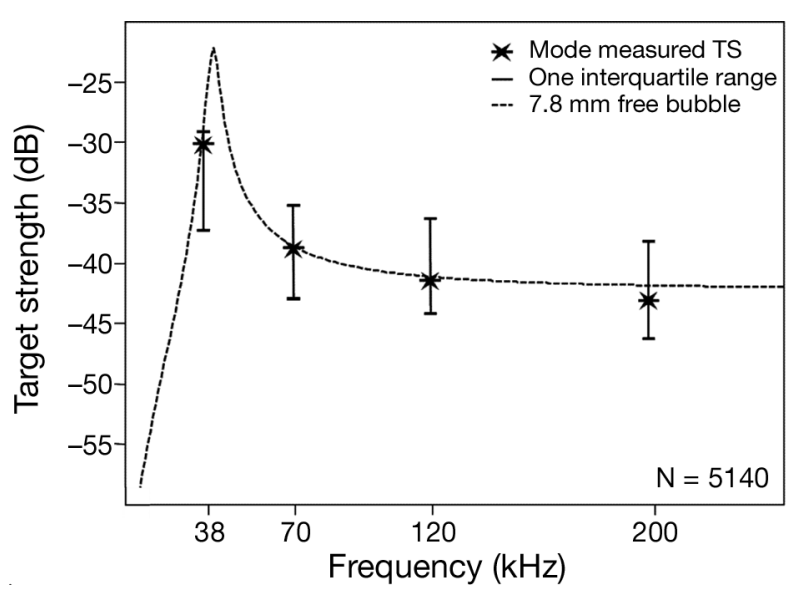

Fig. 2. The mode target strength (TS) of distinctive vertical trails measured at 4 frequencies. Error bars indicate 1 interquartile range. The observed frequency response for each individual trail measured could be accounted for by scattering from free bubbles between 4.7 and $10.8 \mathrm{~mm}$ in diameter. The dashed line in the plot shows the expected target strength of $7.8 \mathrm{~mm}$ free bubbles, which matches the mode distribution of observed target strengths

pling vessel, using linear regressions. A multivariate ANOVA (analysis of variance) was used to evaluate the effects of year, day/night (time of day), sampling zone, and the interaction of day/night and zone on the number of acoustic trail detections per transect. Note that for all statistical analyses of year, only transects within the Pribilof Islands sampling region, which was consistently sampled in both years were included. Night transects were defined as those collected between half an hour after sunset and half an hour before sunrise, while day transects were defined as those between half an hour after sunrise and half an hour before sunset, based on United States Naval Observatory data for the sampling area and dates sampled.

At the individual target level, nearest-neighbor distances were calculated for each echo trail identified. Trails were defined as being part of a single group or aggregation if at least 3 trails were found along the sampling path with nearest-neighbor distances of $<1 \mathrm{~km}$ (a distance selected based on the observed distribution of nearest-neighbor distances). A multivariate ANOVA followed by Bonferroni post hoc analysis was used to examine the effects of year on the number of trails within an aggregation, the horizontal scale of these aggregations, and the nearest-neighbor distance within each aggregation for transects in the Pribilof region.

The relationship between the number of echo trails and the physical and biological habitat were examined in 2 ways. First, an unsupervised 2-step cluster analysis was performed on the transectlevel data. This approach allows both categorical and continuous variables to be considered simultaneously (Zhang et al. 1996) but does not determine the number of clusters a priori; instead, the appropriate number of significant groups is determined statistically. The analysis included (1) categorical variables: year (for the Pribilof region transects), day/night, and sampling zone; and (2) continuous variables: number of trails detected, distance to the nearest colony, a number of prey variables (including krill abundance, median krill depth, pollock abundance, median pollock depth, mean pollock length, and squid abundance) and features of the physical and biological habitat (including sea surface temperature, thermocline depth, stratification, total chlorophyll, maximum chlorophyll, and depth of the chlorophyll maximum). Krill and pollock abundance was obtained from the integrated acoustic data. The median depth of these groups was identified for each transect based on the median depth of the $5 \mathrm{~m} \times 5$ ping bins used for multi-frequency analyses. Because acoustic assessment of squid has yet to be standardized, squid abundance was characterized as the total number of squid per net tow. The second approach used to examine the relationship between echo trails and the habitat was to conduct a multivariate analysis (MANOVA) using the parameters found to be significant in the cluster analysis, with the independent variables of bird trails ( 0 to 1 or $>1$ ), year (for Pribilof region transects), zone, and day/night. This approach allowed possible interactions between these variables to be explored.

To examine the relationship between echo trails and individual patches of krill, a multivariate ANOVA was performed using the independent variables of trail presence/absence, year (for Pribilof region transects), zone, and day/night in relation to the number of patches along each transect and the average patch size, density, and abundance characteristics for each transect. This was followed with an ANOVA to examine the specific prey patch characteristics that were significantly affected by trail presence. ANOVA was also used to examine the effects of zone, day/night, and the interaction of these variables on the depth of krill, pollock, and echo trails. Regression analysis was used to examine the relationship between the maximum depth of each echo trail and the depth characteristics of individual krill patches found at the same location whenever trails and krill patches co-occurred. 


\section{RESULTS}

There was no significant difference in the probability of visually detecting murres or detecting acoustic bubble trails between transects placed randomly and those added adaptively during the cruise $\left(\chi^{2}=\right.$ $0.0178, \chi^{2}=0.0095$, respectively; $\chi_{\text {critical }}^{2}=3.84, \mathrm{df}=1$, $\mathrm{p} \gg 0.05$ for both comparisons). There was a significant positive, linear relationship between the number of acoustic trails showing the distinctive acoustic shape and the frequency response illustrated in Figs. 1 \& 2, with visual observations of all murres within $100 \mathrm{~m}$ of the sampling vessel along each $10 \mathrm{~km}$ long transect (Fig. 3; 2008: $\mathrm{R}^{2}=0.78, \mathrm{~N}=110$; 2009: $\mathrm{R}^{2}=0.81, \mathrm{~N}=141 ; \mathrm{p}<0.05$ for both comparisons). A similar relationship was found when the analysis was conducted for thick-billed murres only (2008: $\mathrm{R}^{2}=0.71, \mathrm{~N}=110 ; 2009: \mathrm{R}^{2}=0.65, \mathrm{~N}=141 ; \mathrm{p}<$ 0.05 for both comparisons), suggesting these trails are caused by diving murres and most often, by diving thick-billed murres, which is in agreement with visual observations that identified approximately $90 \%$ of all murres in both years as thick-billed murres. The frequency response of these echoes is consistent with bubbles leaving the plumage of birds as they dive, accounting for the striking vertical paths as the bubbles ascend above the bird. For the remainder of the present paper, these trails will be referred to as acoustically detected diving birds.

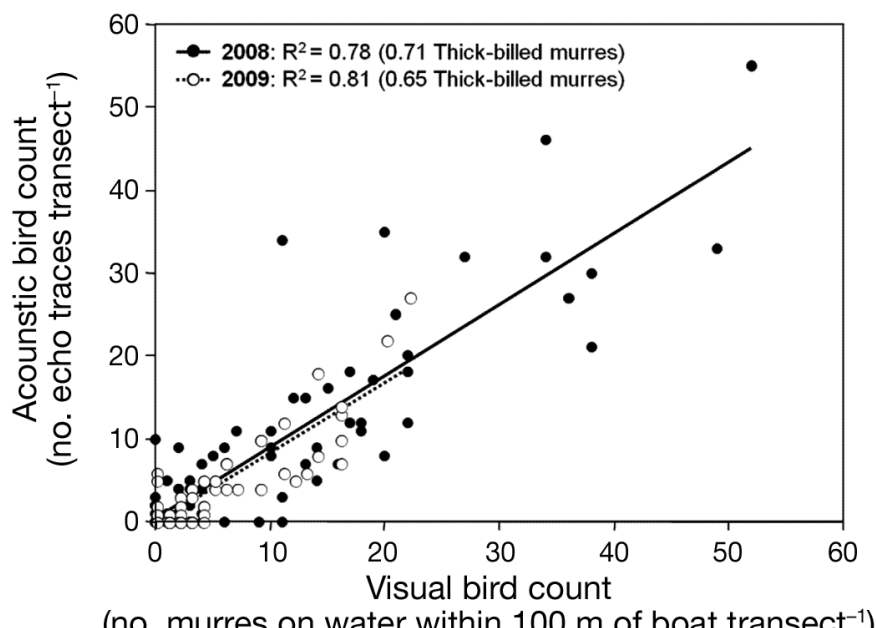

Fig. 3. Relationship between the number of acoustic trail detections per transect and the number of murres Uria spp. detected visually on the water within $100 \mathrm{~m}$ of the starboard side of the survey vessel along the same daytime transect. During both years, the relationship was significant at the 0.05 level. There was no significant difference between the slopes of the regressions between 2008 and $2009(p=0.73)$. Analysis including only birds identified as thick-billed murres $U$. lomvia were also significant, indicating that most acoustically detected diving birds were this species
Within the Pribilof Islands sampling region, there was a significant effect of year on the number of acoustically detected diving birds (multivariate ANOVA; Table 1, Fig. 4B). There was also significant interaction between time of day (day/night) and sampling zone, but no significant main effects of time of day or zone. A post hoc analysis showed that there were significantly fewer diving birds detected acoustically in 2009 than in 2008 (Newman-Keuls; $\mathrm{p}<0.01)$.

The nearest-neighbor distances for acoustically detected diving birds were calculated for all samples whether on transect or in transit to allow distances larger than the $10 \mathrm{~km}$ transect length to be accounted for. There was no significant effect of year (ANOVA, $F=0.09$, df $=1,5139, \mathrm{p}>0.05$ ) on the nearest-neighbor measurements, so all observations were combined to examine the distribution of these measurements. The nearest-neighbor distance distribution was highly skewed, with $>90 \%$ of acoustically detected birds located within $1 \mathrm{~km}$ of a neighboring individual (Fig. 5, inset). More detailed examination revealed that the modal distance between individual acoustically detected birds was $50 \mathrm{~m}$ (Fig. 5). This was quite consistent across observations, with $44 \%$ of the nearest-neighbor distances between 25 and $75 \mathrm{~m}$.

Nearest-neighbor distance measurements suggest that acoustically detected birds were aggregated. We found acoustically detected diving birds in groups of 3 with nearest-neighbor distances of $<1 \mathrm{~km}$ representing $79 \%$ of diving birds in 2008 and $56 \%$ of those detected in 2009. In addition to differences in the fraction of acoustically detected individuals found in aggregations between years, there were also significant inter-annual differences in the number of individuals in each aggregation when log-transformed for normality $(F=3.6$, df $=1,270, \mathrm{p}<0.05)$. In 2008, the average aggregation contained 12.6 individuals, with a maximum of 185 individuals per group, while, in 2009, the average aggregation was only 6.4 individuals, with the largest detected aggregation reach-

Table 1. Multivariate ANOVA on acoustically detected diving murres per transect. ${ }^{*}$ Significant effects $(p<0.05)$

\begin{tabular}{|lrrrr|}
\hline Variable & SS & df & $F$ & p \\
\hline Year & 1186 & 1 & 17.40 & $<0.001^{*}$ \\
Day/night & 113 & 1 & 0.91 & 0.435 \\
Zone & 186 & 2 & 0.73 & 0.578 \\
Day/night $\times$ Zone & 255 & 2 & 3.87 & $<0.05^{*}$ \\
Error & & 235 & & \\
\hline
\end{tabular}




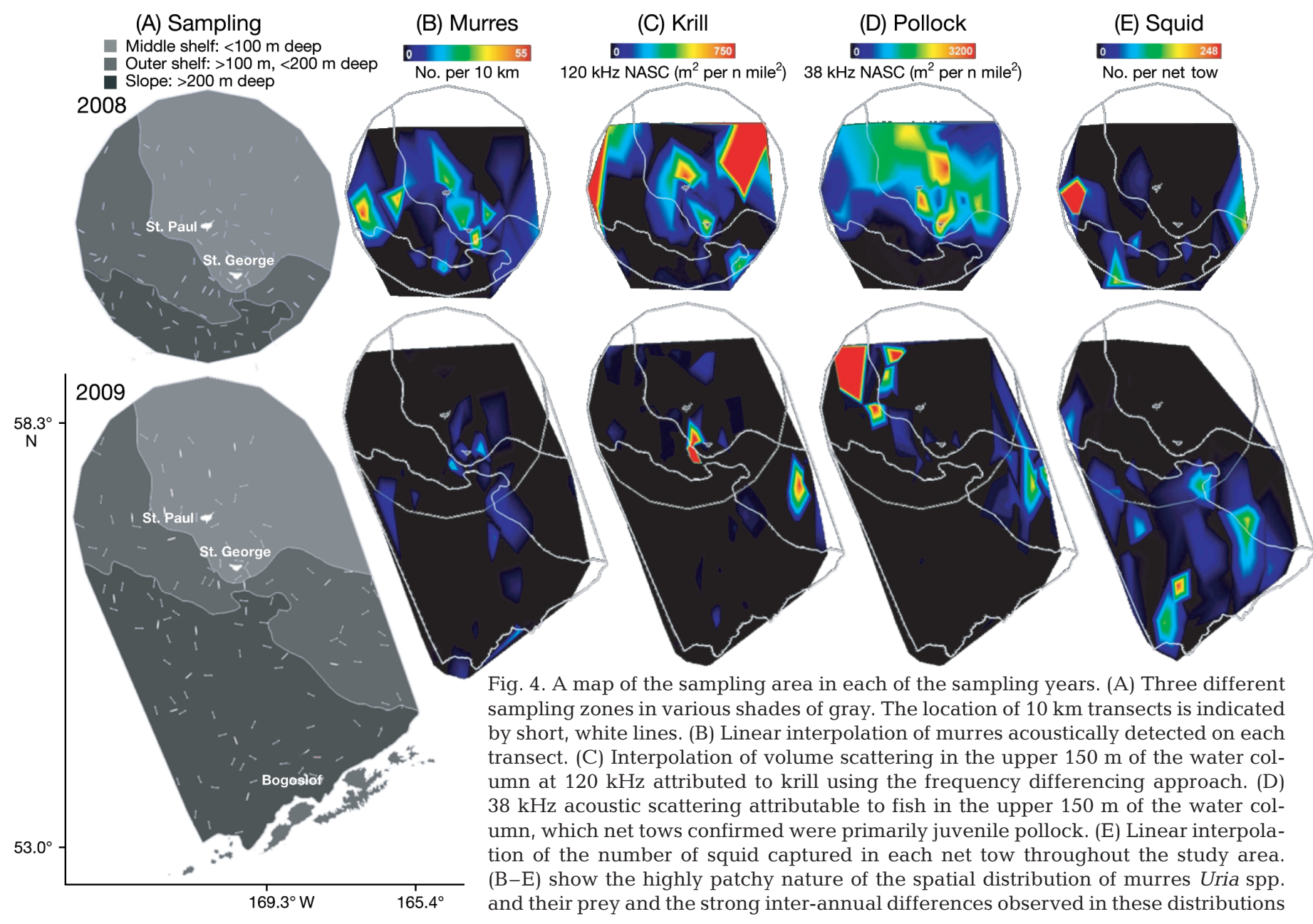

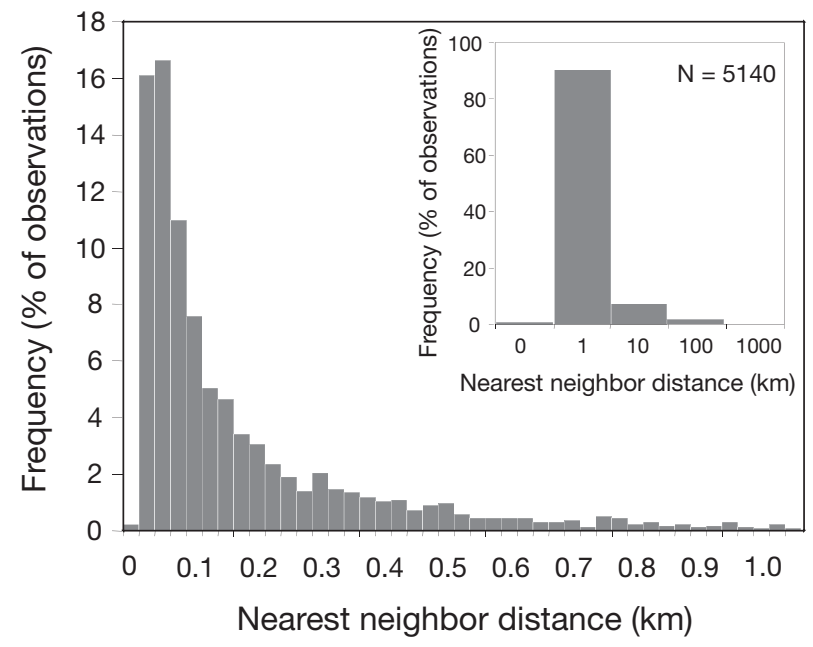

Fig. 5. Uria spp. A histogram of the nearest-neighbor distance for acoustically detected diving birds, including data from transects as well as transits (inset). There was no significant effect of year on the nearest-neighbor distance between birds, so all data are pooled. The larger panel shows the same data out to distances of $1 \mathrm{~km}$, which account for $90 \%$ of all the measured nearest-neighbor distances ing 25 individuals (Fig. 6). There was also a significant difference in the spacing between individuals in aggregations despite the lack of a year effect on the nearest-neighbor distances for the entire population, with mean spacing within a group of $71 \mathrm{~m}$ in 2008 and $138 \mathrm{~m}$ in 2009. However, there was no difference in the horizontal scale of acoustically detected diving bird aggregations between years $(F=0.06, \mathrm{df}=1$, $270, \mathrm{p}>0.05$ ), with mean aggregation extents of $0.75 \mathrm{~km}$ in both years (range: $20 \mathrm{~m}$ to $8 \mathrm{~km}$ ).

A comparison of the area scattering at $120 \mathrm{kHz}$ over the volume sampled by individual net tows with the estimated total biomass of krill in the tow showed a significant, positive, linear relationship $\left(\mathrm{R}^{2}=0.57\right.$, $\mathrm{p}<0.05$ ) supporting the use of this acoustic measure as a proxy for the abundance of krill at scales that could not be physically sampled. The comparison between the $38 \mathrm{kHz}$ area scattering over the volume sampled by the net and the total biomass of pollock also showed a significant, positive, linear relationship $\left(R^{2}=0.74, p<0.05\right)$. The addition of other fish 


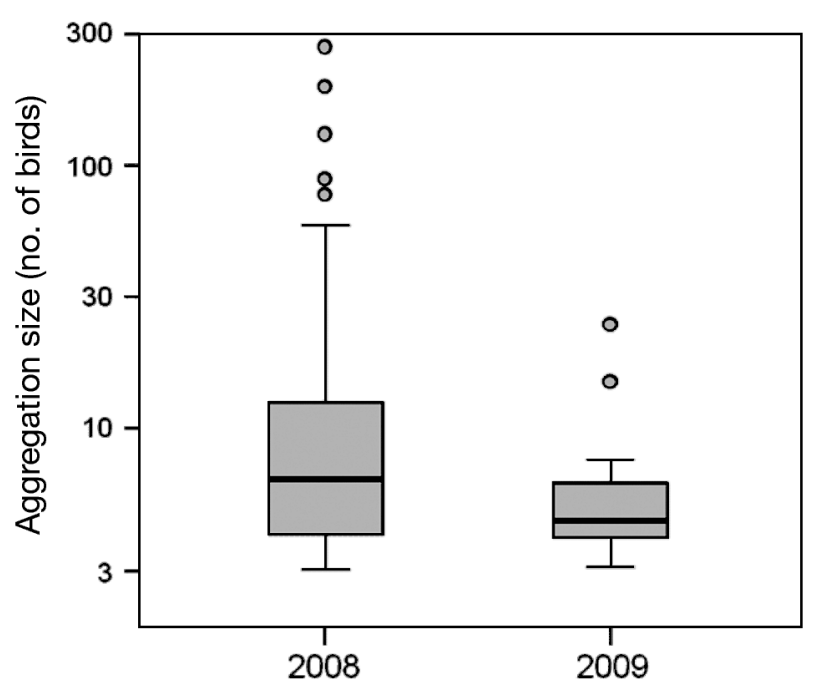

Fig. 6. Uria spp. The size of aggregations of acoustically detected diving murres. Central lines show the median, gray boxes show 1 interquartile range, the error bars show the $95 \%$ confidence interval, and dots show outliers. Note that the $y$-axis is on a logarithmic scale. There was a significant effect of year on aggregation size. In addition, in 2008, $79 \%$ of detected murres were in aggregations, versus only $56 \%$ in 2009

groups did not improve the fit of the relationship between $38 \mathrm{kHz}$ scattering and fish biomass, suggesting that the $38 \mathrm{kHz}$ scattering from fish can reasonably be assumed to be primarily from walleye pollock, similar to the results of other acoustic surveys in the same area (De Robertis 2010).

These proxy measures for the abundance of krill and pollock, as well as counts of squid from net tows, show that these prey groups are extremely patchy (Fig. 4C-E) and are unlikely to show relationships to acoustically detected diving birds individually as the birds are capable of switching prey amongst these groups. To account for the characteristics of the entire prey field and other characteristics of the habitat simultaneously, an unsupervised 2-step cluster analysis with Bonferroni corrections for multiple comparisons was employed on the transect-level data. The analysis split the transects into 2 statistical clusters which were defined by the continuous variable 'number of acoustically detected diving birds', with 1 group having 0 or 1 diving birds $\left(\mathrm{N}=160, t_{\text {corrected }}=-4.2, \mathrm{p}<0.01\right)$ and the other having $>1$ diving bird $\left(\mathrm{N}=82, t_{\text {corrected }}=1.1\right.$, $\mathrm{p}<0.01$ ). Each of the categorical variables (year, day/night, zone) had a significant effect on the classification $\left(\chi^{2}=15.1,16.2,14.3\right.$, respectively, $p<0.05$ for each variable). There was no significant effect of distance from the nearest breeding colony; however, transects with 0 or 1 acoustic bird trails occurred primarily during the day, and $62 \%$ were in the middle of the shelf where water was $<100 \mathrm{~m}$ deep. Transects with $>1$ acoustic bird trail were observed at night $66 \%$ of the time. Transects with multiple acoustically detected bird trails were found most often on the outer shelf $(64 \%)$ and slope $(31 \%)$, while only $5 \%$ of multiple bird detections occurred on the mid-shelf. Of the environmental variables, none of the biological habitat variables significantly affected the classification, and of the physical habitat variables, only seasurface temperature significantly impacted the classification $\left(t_{0-1 \text { birds }}=4.4, \mathrm{p}<0.05 ; t_{>1 \text { bird }}=-2.9\right)$, with transects with 0 or 1 acoustically detected bird trails having a higher mean temperature than those with $>1$ bird trail $\left(9.7\right.$ vs. $7.6^{\circ} \mathrm{C}$, respectively). Of the prey characteristics, only pollock length did not significantly affect the classification. For all 3 prey types, the abundance of prey was significantly lower than the overall prey abundance for transects that had 0 or 1 diving birds. However, the abundance of each individual prey type was not significantly higher than expected for transects with $>1$ bird. The depths of both krill and pollock were significantly shallower than expected on transects with 2 or more diving birds and significantly deeper than expected along transects with 0 or 1 diving bird (Fig. 7). Significant continuous variables (threshold significance of 0.05) in rank order of importance to the classification were: krill depth, pollock depth, sea-surface temperature, squid abundance, krill abundance, and pollock abundance.

Multivariate analysis of these variables using the factors year, zone, and day/night, as well as the classes of murres defined by the cluster analysis $(0$ or 1 acoustically detected diving birds and $>1$ acoustically detected diving bird) supported the conclusion that murre abundance, as well as the factors year, zone, and day/night had significant effects on the response variables of krill depth, pollock depth, seasurface temperature, squid abundance, krill abundance, and pollock abundance, but also allowed the interactions among the independent variables to be explored (Table 2). The only significant interaction observed was acoustically detected diving bird presence with time of day and sampling zone.

While only $25 \%$ of the surveyed area in 2008 and $12 \%$ of the surveyed area in 2009 had krill, $42 \%$ of diving birds detected in 2008 and $57 \%$ of those detected in 2009 horizontally overlapped with patches of krill (e.g. were found at the exact same horizontal location). A multivariate analysis was conducted to examine the factors affecting the number of patches along each transect and the size, depth, and density characteristics of krill patches (Table 3). This analysis showed significant inter-annual differences with 

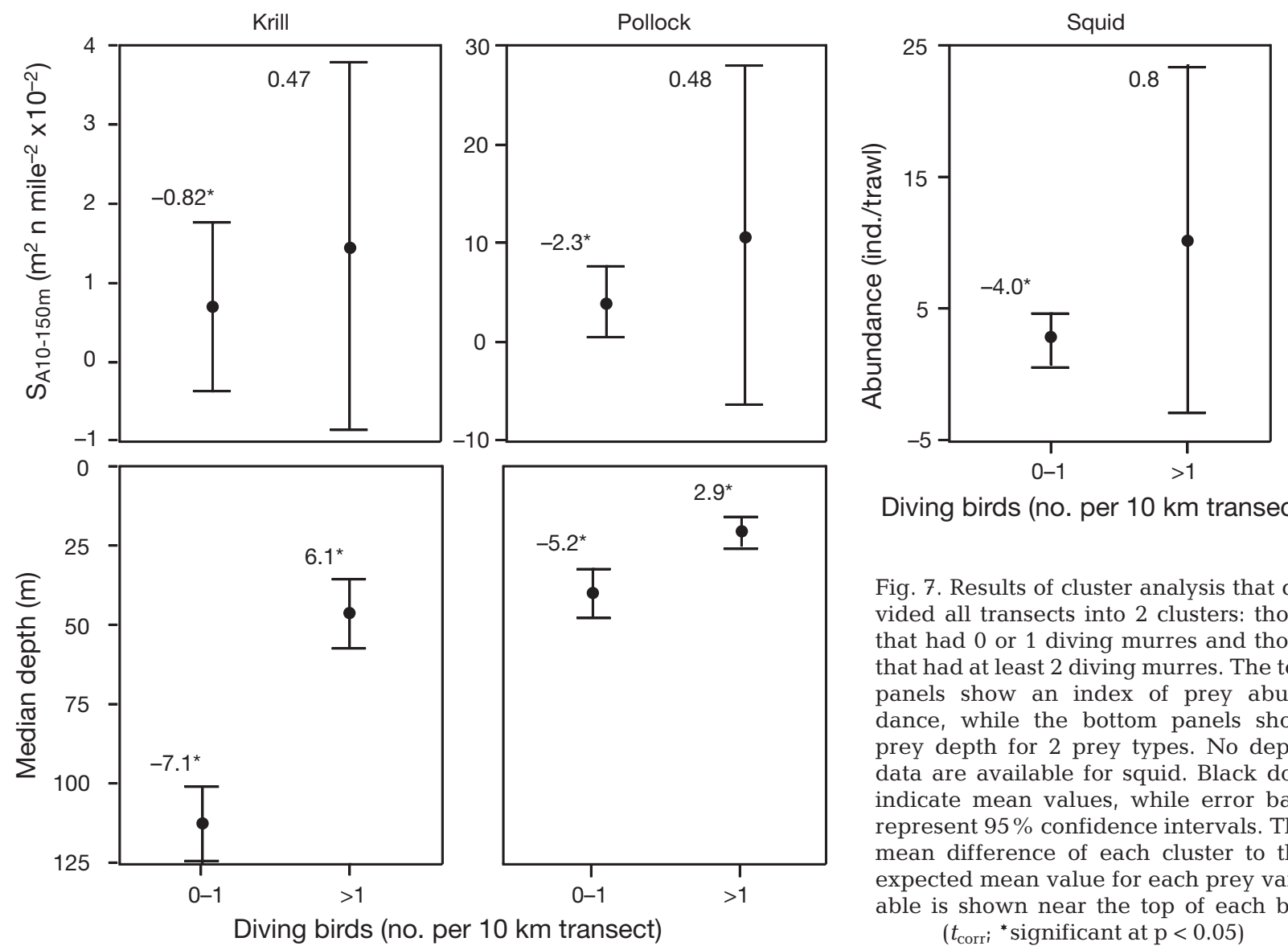

Diving birds (no. per $10 \mathrm{~km}$ transect)

Fig. 7. Results of cluster analysis that divided all transects into 2 clusters: those that had 0 or 1 diving murres and those that had at least 2 diving murres. The top panels show an index of prey abundance, while the bottom panels show prey depth for 2 prey types. No depth data are available for squid. Black dots indicate mean values, while error bars represent $95 \%$ confidence intervals. The mean difference of each cluster to the expected mean value for each prey variable is shown near the top of each bar $\left(t_{\text {corri }}{ }^{*}\right.$ significant at $\left.\mathrm{p}<0.05\right)$

$40 \%$ less krill biomass in 2009 than in 2008. The krill in 2009 were found in larger, shallower, lower density patches than in 2008. Krill patches also varied with sampling zone, with the largest, densest patches on the outer shelf in both years (between 100 and $200 \mathrm{~m}$ bottom depth). In both years, there was a significant diel effect, with krill patches about $60 \mathrm{~m}$ shallower at night than during the day, with significantly higher mean and maximum krill densities during the day than during the night. There was a significant effect of acoustic bird trail presence on krill

Table 2. Results of a MANOVA on murre habitat and prey characteristics at the transect level. *Significant effects $(p<0.05)$

\begin{tabular}{|lccccc|}
\hline Variable & $\begin{array}{c}\text { Wilks' } \\
\text { lambda }\end{array}$ & $F$ & $\begin{array}{c}\text { Hypo- } \\
\text { thesis df }\end{array}$ & $\begin{array}{c}\text { Error } \\
\text { df }\end{array}$ & $\mathrm{p}$ \\
\hline Birds $(0-1$ or $>1)$ & 0.917 & 3.329 & 5 & 223 & $<0.01^{*}$ \\
Year & 0.907 & 4.578 & 5 & 223 & $<0.001^{*}$ \\
Zone & 0.835 & 4.194 & 10 & 446 & $<0.0001^{*}$ \\
Day/night & 0.861 & 7.211 & 5 & 223 & $<0.0001^{*}$ \\
Birds $\times$ Year & 0.975 & 1.121 & 5 & 223 & 0.35 \\
Birds $\times$ Day/night & 0.979 & 0.972 & 5 & 223 & 0.44 \\
Birds $\times$ Day/night $\times$ Zone & 0.814 & 1.589 & 30 & 894 & $<0.01^{*}$ \\
\hline
\end{tabular}

patch number and characteristics (summarized in Table 4). Krill patches that contained acoustic bird trails had a 7 -fold greater mean krill density (1050 vs. $143 \mathrm{krill} \mathrm{m}^{-3}$ ), a 6 -fold greater maximum krill density (15770 vs. $2763 \mathrm{krill} \mathrm{m}^{-3}$ ), and were significantly shallower (mean patch depth 61 vs. $66 \mathrm{~m}$ ) than patches that did not contain bird trails. However, there were no significant differences based on bird presence on the integrated krill abundance in each patch or any of the patch size characteristics (horizontal mean: $1 \mathrm{~km}$, vertical mean: $5 \mathrm{~m}$, and area mean: $23000 \mathrm{~m}^{2}$ ) or the distance of these patches to the nearest colony.

In addition to examining the horizontal patterns in prey and acoustic bird trails, with acoustic analyses it is also possible to examine the vertical distribution patterns in predators and prey. First, a multivariate ANOVA was used to examine the effects of year, zone, and day/ night on the mean depth of pollock and krill and on the transect-averaged maximum observed depth of acoustically detected 
diving bird trails (Table 5, Fig. 8). There was significant interaction between time and zone on the depth of acoustically observed diving murres. There were significant main effects of time and zone on the depth

Table 3. Multivariate test results on krill patch characteristics as a function of year, day/night, zone, and acoustically detected presence/absence of diving murres. * Significant effects $(\mathrm{p}<0.05)$

\begin{tabular}{|lccccc|}
\hline Effect & $\begin{array}{c}\text { Wilks' } \\
\text { lambda }\end{array}$ & $\begin{array}{c}\text { Hypo- } \\
\text { thesis df }\end{array}$ & $\begin{array}{c}\text { Error } \\
\text { df }\end{array}$ & p \\
\hline Year & 0.831 & 5 & 9 & 210 & $<0.001^{*}$ \\
Day/night & 0.820 & 5 & 9 & 210 & $<0.001^{*}$ \\
Zone & 0.846 & 1 & 18 & 420 & $<0.05^{*}$ \\
Bird trail presence/absence & 0.881 & 3 & 9 & 210 & $<0.001^{*}$ \\
Year $\times$ Day/night & 0.957 & 1 & 9 & 210 & 0.41 \\
Year $\times$ Zone & 0.900 & 1 & 18 & 420 & 0.21 \\
Year $\times$ Birds & 0.984 & 0 & 9 & 210 & 0.94 \\
Day/night $\times$ Zone & 0.880 & 2 & 18 & 420 & 0.07 \\
Day/night $\times$ Birds & 0.938 & 2 & 9 & 210 & 0.14 \\
Zone $\times$ Birds & 0.942 & 1 & 18 & 420 & 0.81 \\
Year $\times$ Day/night $\times$ Zone & 0.922 & 1 & 18 & 420 & 0.50 \\
Year $\times$ Day/night $\times$ Birds & 0.929 & 2 & 9 & 210 & 0.07 \\
Year $\times$ Zone $\times$ Birds & 0.898 & 1 & 18 & 420 & 0.19 \\
Day/night $\times$ Zone $\times$ Birds & 0.952 & 1 & 18 & 420 & 0.91 \\
Year $\times$ Day/night $\times$ Zone $\times$ Birds & 0.919 & 1 & 18 & 420 & 0.45 \\
\hline
\end{tabular}

of krill, while there was a significant time by zone interaction effect on pollock depth. Because murres are capable of switching among prey types, acoustically detected diving bird trails were split approximately in half into those that horizontally overlapped with patches of krill and those that did not (Fig. 9). There was a significant difference in the depth distribution of these 2 groups of bird trails (ANOVA: $F=3.89$, df $=1,5138, \mathrm{p}<0.01$ ), with birds found within krill patches significantly deeper than those found outside of krill patches. There was no significant difference in the depth distribution of bird trails found outside of krill patches (Fig. 9C) with the overall depth distribution of pollock (Fig. 9D; ANOVA: $F=0.12, \mathrm{df}=1,2806, \mathrm{p}>0.05$ ). Regression analysis was used to examine the relationship between individual birds that were horizontally overlapping with patches of krill and various measures of krill depth. The variable that explained most of the variation in the maximum

Table 4. Multivariate ANOVA results on the effects of murre presence/absence on krill patch characteristics along each transect. ${ }^{*}$ Significant effects $(\mathrm{p}<0.05)$

\begin{tabular}{|c|c|c|c|c|c|}
\hline Krill characteristics & Grouping & SS & $\mathrm{df}$ & $F$ & $\mathrm{p}$ \\
\hline Distance from nearest colony & $\begin{array}{l}\text { Between groups } \\
\text { Within groups } \\
\text { Total }\end{array}$ & $\begin{array}{r}811 \\
327401 \\
328212\end{array}$ & $\begin{array}{r}1 \\
240 \\
241\end{array}$ & 0.48 & 0.47 \\
\hline Number of patches & $\begin{array}{l}\text { Between groups } \\
\text { Within groups } \\
\text { Total }\end{array}$ & $\begin{array}{r}439 \\
217976 \\
218416\end{array}$ & $\begin{array}{r}1 \\
240 \\
241\end{array}$ & 0.48 & 0.49 \\
\hline Total abundance & $\begin{array}{l}\text { Between groups } \\
\text { Within groups } \\
\text { Total }\end{array}$ & $\begin{array}{r}579298 \\
181948827 \\
182528125\end{array}$ & $\begin{array}{r}1 \\
240 \\
241\end{array}$ & 0.76 & 0.38 \\
\hline Mean density & $\begin{array}{l}\text { Between groups } \\
\text { Within groups } \\
\text { Total }\end{array}$ & $\begin{array}{r}6221 \\
185816 \\
188038\end{array}$ & $\begin{array}{r}1 \\
240 \\
241\end{array}$ & 3.87 & $<0.05^{*}$ \\
\hline Maximum density & $\begin{array}{l}\text { Between groups } \\
\text { Within groups } \\
\text { Total }\end{array}$ & $\begin{array}{r}2965 \\
117717 \\
119682\end{array}$ & $\begin{array}{r}1 \\
240 \\
241\end{array}$ & 4.01 & $<0.05^{*}$ \\
\hline Mean height & $\begin{array}{l}\text { Between groups } \\
\text { Within groups } \\
\text { Total }\end{array}$ & $\begin{array}{r}53 \\
15276 \\
15329\end{array}$ & $\begin{array}{r}1 \\
240 \\
241\end{array}$ & 0.83 & 0.36 \\
\hline Mean depth & $\begin{array}{l}\text { Between groups } \\
\text { Within groups } \\
\text { Total }\end{array}$ & $\begin{array}{r}0 \\
556951 \\
556951\end{array}$ & $\begin{array}{r}1 \\
240 \\
241\end{array}$ & 6.01 & $<0.01^{*}$ \\
\hline Mean length & $\begin{array}{l}\text { Between groups } \\
\text { Within groups } \\
\text { Total }\end{array}$ & $\begin{array}{r}3749689 \\
918439754 \\
922189443\end{array}$ & $\begin{array}{r}1 \\
240 \\
241\end{array}$ & 0.98 & 0.32 \\
\hline Mean area & $\begin{array}{l}\text { Between groups } \\
\text { Within groups } \\
\text { Total }\end{array}$ & $\begin{array}{r}7860472935 \\
1118439418801 \\
1126299891736\end{array}$ & $\begin{array}{r}1 \\
240 \\
241\end{array}$ & 1.69 & 0.20 \\
\hline
\end{tabular}


depth of individual bird trails was the minimum depth of the krill patch in which it was found. There was a significant exponential relationship between these 2 variables (Fig. 10) so that birds diving to shallow krill patches were diving past the upper edge of the krill patch, while when krill patches were found deeper in the water column, murres dove just to the krill's upper edge. Based on an exponential regression, $76 \%$ of the variation in bird trail maximum depth could be accounted for by the minimum depth of the krill patch at the same location ( $p<$ 0.001).
Table 5. Multivariate ANOVA on the median depth along each transect of pollock, krill, and acoustically detected diving murres. ${ }^{*}$ Significant effects $(\mathrm{p}<0.05)$

\begin{tabular}{|lcrrrc|}
\hline \multirow{2}{*}{ Factor } & Dependent variable & SS & df & $F$ & p \\
\hline Year & Pollock depth & 1671 & 1 & 3.91 & 0.25 \\
& Krill depth & 1383 & 1 & 2.49 & 0.12 \\
Zone & Bird depth & 1892 & 1 & 1.66 & 0.34 \\
& Pollock depth & 3484 & 3 & 2.09 & 0.11 \\
& Krill depth & 1025 & 3 & 2.58 & $0.05^{*}$ \\
Day/night & Bird depth & 4476 & 3 & 1.85 & 0.22 \\
& Pollock depth & 570 & 1 & 3.08 & 0.13 \\
Year $\times$ Zone & Krill depth & 16569 & 1 & 29.79 & $<0.0001^{*}$ \\
& Bird depth & 1178 & 1 & 5.43 & 0.25 \\
Year $\times$ Day/night & Pollock depth & 230 & 2 & 0.67 & 0.51 \\
& Krill depth & 800 & 2 & 1.32 & 0.16 \\
& Bird depth & 187 & 2 & 0.51 & 0.62 \\
& Pollock depth & 96 & 1 & 0.56 & 0.46 \\
& Krill depth & 328 & 1 & 0.98 & 0.16 \\
& Bird depth & 118 & 1 & 0.71 & 0.34 \\
Zone $\times$ Day/night & Pollock depth & 11771 & 2 & 10.58 & $<0.0001^{*}$ \\
& Krill depth & 130 & 2 & 0.38 & 0.69 \\
& Bird depth & 4767 & 2 & 4.87 & $<0.001^{*}$ \\
& Pollock depth & 19374 & 235 & & \\
& Krill depth & 62844 & 235 & & \\
& Bird depth & 24509 & 235 & & \\
& & & & & \\
& & & & & \\
& & &
\end{tabular}

\section{DISCUSSION}

\section{Detecting diving birds}

Active acoustics provides a new approach to studying the ecology of diving seabirds. While diving birds have been shown to be detectable using sonar (Hunt et al. 1996, Axelsen et al. 2001, Brierley \& Fernandes 2001), and Axelsen et al. (2001) used acoustics to qualitatively examine the relationship between seabird predators and their prey, this is the first published account using quantitative fisheries acoustics techniques to examine seabird-prey interactions. Several advantages of using fisheries acoustics techniques are apparent: (1) the approach is non-invasive; (2) in addition to bird horizontal position, it allows the depth of birds to be measured up to about $200 \mathrm{~m}$; (3) it is not limited by visual conditions like fog and darkness; (4) it excludes nondiving birds that are not actively foraging; (5) it has the potential for large sam-
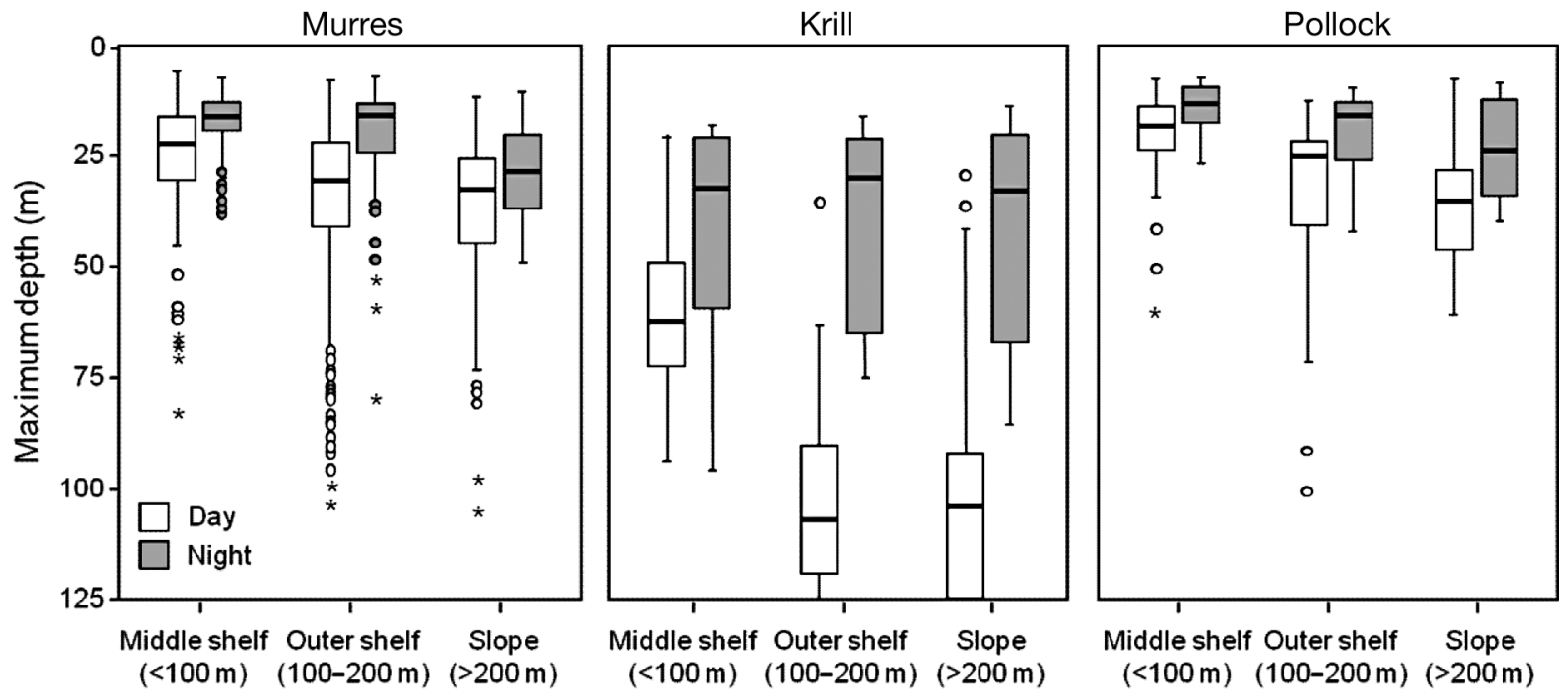

Fig. 8. The depth distribution of murres and 2 of their primary prey as a function of sampling zone and time of day. Horizontal lines show the median depth, boxes show 1 interquartile range, error bars show the $95 \%$ confidence interval, and dots show outliers 


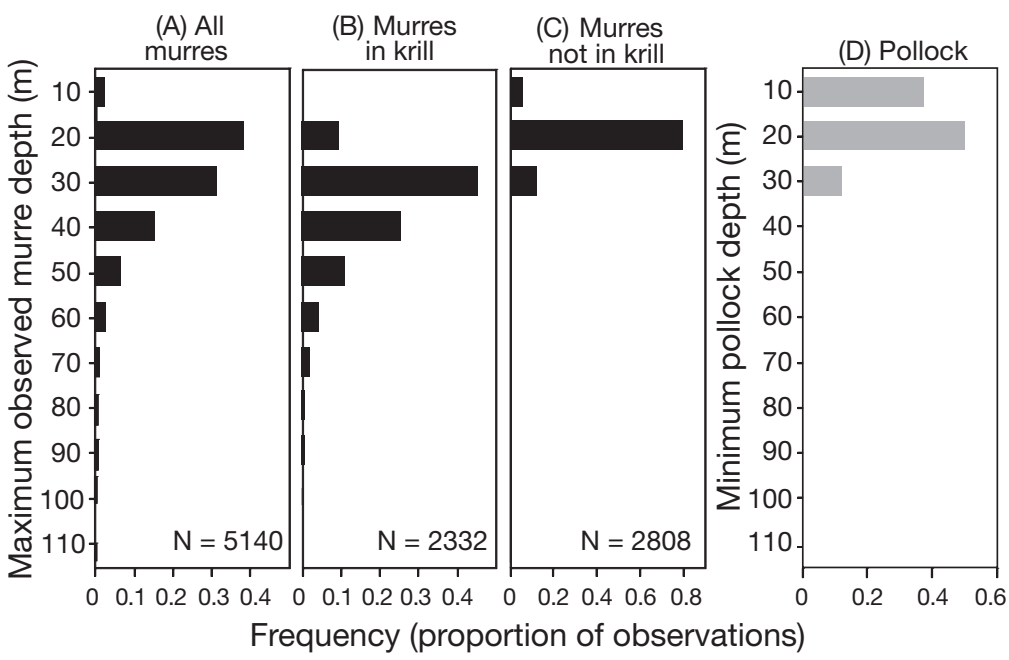

Fig. 9. (A-C) Depth distribution of murres for both years (2008 and 2009) over the entire study area. (D) Depth distribution of pollock from both years and all areas combined

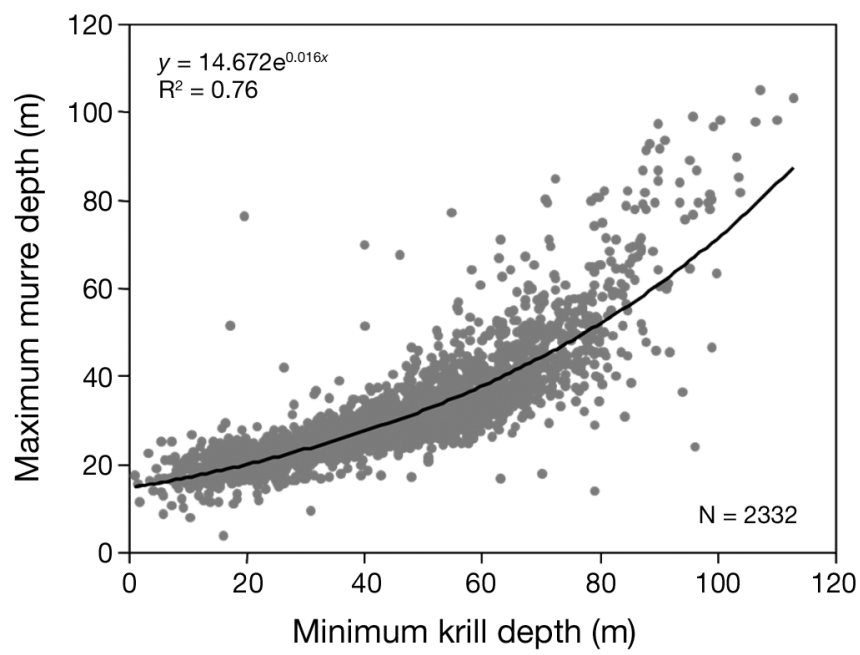

Fig. 10. Relationship between the maximum depth observed for individually detected diving murres as a function of the minimum depth of the krill patch which they horizontally overlapped

ple sizes, allowing population level responses to be observed ( $\mathrm{N}=5140$ in the present study); and (6) it allows simultaneous sampling of birds and the quantification of the type, depth, distribution, and density of potential prey, permitting the horizontal and vertical overlap between predator and prey to be examined at the same resolution and scale. However, this technique will only be applicable to some bird species, and, in the same way that prey data must be appropriately sea-truthed using direct sampling approaches, acoustic observations of birds must also be sea-truthed. In this case, acoustic observations of bubble trails were paired with daytime surveys for birds (Fig. 3). Both approaches provide strip-transect data and thus, when appropriately scaled, can be compared directly for numbers of individuals detected, providing species identifications from the visual surveys which complemented the classifications based on echo characteristics. We found that echo trails that exceeded $10 \mathrm{~m}$ in depth and had the frequency response shown in Fig. 2 were strongly correlated with the presence of murres on the water within $100 \mathrm{~m}$ of the boat. In fact, during the daytime, the numbers of birds identified visually and those identified acoustically showed nearly a 1:1 relationship at this scale, suggesting that, in this area, the number of murres on the water is indicative of the number of birds diving. Further analysis showed that most of the birds detected acoustically were thick-billed murres $U$. lomvia as a comparison of acoustically detected birds and only this species was also quite strong statistically.

Diving murres present intense echo trails that have a unique frequency response consistent with resonance from small (4.7 to $10.8 \mathrm{~mm}$ ) free bubbles leaving the plumage of diving birds as has been observed visually in murre species. Because of their formation mechanism, these trails are extremely small in horizontal extent, requiring acoustic data collection at a high sampling rate to observe them. In the present study, the deepest individual diving murre was detected at $115 \mathrm{~m}$, which is consistent with depths recorded by Takahashi et al. (2008), but substantially less than the maximum dive for tagged thick-billed murres of $210 \mathrm{~m}$ observed by Croll et al. (1992). The differences in maximum recorded dive depths could potentially be attributed to our observing only a single point within a dive acoustically, thus ignoring descent and ascent. However, observations of tagged animals show that most of each dive is spent at or near the dive's maximum depth (Croll et al. 1992), suggesting that, with the sample size we have available, the maximum depth detected in our work likely represents the typical maximum diving depth for murres around the Pribilof and Bogoslof Islands (Takahashi et al. 2008).

\section{Murre habitat use}

Despite highly similar observed patterns in physical structure of the habitat during 2008 and 2009, 
there was a significant difference in the number of diving murres detected between years, with fewer birds acoustically detected in 2009 (Table 1). In both years, the horizontal distribution of echo trails showed that most murres were aggregated (Figs. 5 \& 6). Nearly $3 / 4$ of all birds were found in groups of 3 or more individuals, with nearest-neighbor distances of $<1 \mathrm{~km}$. However, significantly fewer birds were in aggregations in 2009, and each of these aggregations was made up of significantly fewer individuals spaced farther apart, resulting in aggregations of murres that were similar in total horizontal extent in both years. Despite the statistical identification of aggregations of diving murres, observers noted few distinctive 'feeding flocks' while counting birds at sea in either year. This is likely due to the spacing of individuals, which was highly consistent each year, with a mode of $50 \mathrm{~m}$ along a transect with nearly all diving individuals between 25 and $75 \mathrm{~m}$ from their nearest neighbor. The spacing of diving birds acoustically observed in aggregations equates to visually observing 1 bird every $20 \mathrm{~s}$, and thus from the scale and perspective afforded by the methods used, is not easily perceived as an aggregation while underway at sea.

The number of diving birds detected was also significantly affected by the sampling zone's interaction with time of day (Table 1). Individual (nonaggregated) diving murres were more likely to be found alone in shallow water $(<100 \mathrm{~m})$ during the day, whereas aggregations of birds were more likely to be found in the outer shelf and slope zones (>100 m) at night. This suggests that murres use different tactics when foraging on prey in different habitats and likely reflects the differences in diet noted during the same time period, with parents feeding their chicks small fish that could be caught near the colony while consuming krill and squid that are primarily accessible in deep waters, far from the colonies at night. There was, however, no significant difference in the rate of bird detections during the day and night, suggesting that both periods are important for foraging despite these different tactics. These results indicate that using only daytime observations of murres as an index of habitat use and foraging activity can significantly skew any results drawn from those data, underestimating the importance of deepwater habitats and making the calculation of accurate energy budgets impossible.

We found that of all the biological and physical habitat variables we examined, only sea-surface temperature significantly affected the classification of transects into those with 0 or 1 acoustically detected birds and those with more birds. However, sea-surface temperature co-varied with sampling zone, which was also significant in the classification, and removing either from the analysis did not affect the outcome or the rank order importance of the other variables. The relationship between temperature and the number of diving birds may also be explained by increased diving time per bout at higher sea-surface temperatures as observed by Takahashi et al. (2008) in the same area, resulting in our higher encounter rates with diving birds. Based on these results, murres do not seem to be cuing in on some easily sensed physical habitat variable as observed in other studies (Decker \& Hunt 1996, Takahashi et al. 2008) or using local knowledge to find prey associated with re-locatable oceanographic features within the study area (Coyle et al. 1992).

\section{Murres and broad-scale prey characteristics}

The most important determinants of the classification of transects by bird abundance were prey characteristics. The plasticity of the diet and foraging tactics of thick-billed murres necessitated that analysis of the relationships between murres and their prey simultaneously consider multiple prey types and the vertical distributions of these prey types. This contrasts with many previous seabird studies that include only a single prey type at a time, and most have not evaluated the importance of prey depth. Of the prey characteristics tested, only the length of individual pollock did not significantly affect the classification. Shallower krill and pollock were associated with transects containing 2 or more diving murres, which suggests that vertical accessibility of prey is important for the detection or selection of prey by murres (Fig. 7). The effects of depth, however, were quite different for these 2 prey groups. Pollock in areas with 2 or more diving birds were only $15 \mathrm{~m}$ shallower than in those areas that contained 0 or 1 birds, whereas the depth differences for krill in the presence and absence of bird aggregations was $60 \mathrm{~m}$. Krill patches in areas with 2 or more birds were $30 \mathrm{~m}$ deeper than pollock patches in the absence of birds and from 8 to $10 \mathrm{~m}$ deeper than pollock patches associated with 2 or more birds. This indicates that either the value of these 2 prey groups or the costs of foraging on these different prey is not equal.

In addition to vertical prey accessibility, the abundance of squid, krill, and pollock had significant effects in the classification analysis (Fig. 7). While transects with no or only 1 bird had low abundances of all of these prey groups, those tran- 
sects that had 2 or more diving birds did not necessarily have a significantly higher abundance of all prey groups; rather, they had a very broad distribution of prey abundance of each group. This is because while 1 prey group on a given transect containing 2 or more birds may have been in high abundance, the other prey groups typically were not. Conversely, on another transect containing 2 or more birds, a different prey group might be in high abundance, resulting in high variability within a single prey group when the transects are combined (Fig. 4). This result shows that, at the population level, murres were prey-switching during the study. This could be the result of individual birds varying their own diet, having a different diet from what they feed their offspring, or specialization by individuals in the population.

To further examine the effects of year, zone, time of day, and bird presence, as well as their interactions on prey characteristics, a multivariate analysis was conducted (Table 2). Although each of the variables had a significant effect individually, the only significant interaction observed was between acoustically detected diving bird presence, time of day, and sampling zone. This indicates that murres use different tactics when foraging on prey in different habitats and at different times of the day. The difference in foraging tactics is also clearly shown by the diving depths observed in murres (Fig. 8, Table 5), which change with the interaction of zone and time. These changes in the behavior of murres is likely a response to changes in the vertical distribution of 2 of their major prey, pollock and krill, which both undergo diel vertical migrations, the magnitudes of which change with bottom depth, as well as changes in the costs and benefits of foraging for their chicks versus themselves.

\section{Murres in prey patches}

Examining the individual prey groups at scales smaller than an individual transect leads to further insights about murre foraging. Krill were typically found in discrete patches that ranged in horizontal scale from $5 \mathrm{~m}$ to just over $10 \mathrm{~km}$ and had a vertical extent ranging from 1 to $96 \mathrm{~m}$. Most patches of krill were found mid-water, in contrast to the epibenthic aggregations of krill observed by Coyle et al. (1992). In 2009, there were significantly fewer krill than in 2008, but these krill were in larger, shallower patches with lower numerical density. In both years, patches were on average $60 \mathrm{~m}$ shallower at night than during the day and were significantly less dense at night than during the day, although the strength of these changes varied with sampling zone (Table 3 ).

In addition to the effects of year, zone, and time of day, krill patch characteristics were significantly affected by the presence of acoustically detected diving murres (Table 4). Murres diving on krill patches dove on patches that had higher mean krill densities, higher maximum krill densities, and were shallower than krill patches detected in the absence of murres. However, there was no significant effect of bird presence on the total integrated abundance of krill within each patch or in any of the patch size characteristics. One interpretation of these results could be that krill change their distributions in response to diving birds. However, krill patches would have to change mean densities by an order of magnitude without changing their spatial extent while moving up in the water column by $5 \mathrm{~m}$ to explain the observed pattern. Instead, these results suggest selection of patches by murres using the numerical density of krill within a patch and the vertical accessibility, not the total krill abundance within a patch or the size of the patch. This contrasts with theoretical predictions that large patches should be more likely to be targeted by predators than small patches of equal quality (Milne et al. 1989). The observed patch selection pattern by diving murres did not vary with year, as there was no significant interaction between year and diving bird presence. The significant interaction effect between zone, time of day, and bird presence, but the lack of a significant interaction between time of day and bird presence shows that birds are selecting patches with similar characteristics both day and night, but are doing so at different places within the study area.

The correlation of murres with krill density and depth, but not any krill patch size characteristics shows that the common approach of using constantsized boxes at different scales to examine predatorprey overlap (e.g. Piatt 1990) or other statistical approaches that identify scale-specific relationships would not have worked during the present study because absolute patch size was apparently unimportant to krill patch selection by murres. Correlations with prey characteristics were apparent only when the relationship of murres to krill was considered at the scale of an individual krill patch regardless of its horizontal size. Similar results have been observed in examining correlations with other marine predators and their prey (Veit et al. 1993, BenoitBird \& Au 2003, Benoit-Bird et al. 2004), indicating that alternative statistical approaches to gridded 
analyses or other spatially explicit approaches may be necessary in these systems to identify predatorprey relationships.

\section{Predator and prey vertical relationships}

All of the analyses of the relationship between murres and their prey indicate the importance of prey depth. To examine this in further detail, the depths of individual diving murres found to horizontally overlap with a patch of krill were examined in relation to the depth of that patch. A strong relationship was found between the depth of individual diving birds and the minimum depth of the krill patch they were found in (Fig. 10). However, this relationship was not linear. When patches of krill were shallow, murres dove deeper than the shallowest edge of the patch. When patches of krill were deep, murres were found just at the upper edge of the patch. Combining this pattern with the significantly weaker correlations between murre depth and the mean or maximum depth of the krill patch indicates that the upper limit of krill is the important characteristic for determining murre patch use. This is not surprising given the increasing costs of diving that murres face with increasing depth (Croll et al. 1992). The costs of diving appear to increase most dramatically after $80 \mathrm{~m}$ depth (Croll et al. 1992), which is roughly the point at which non-linearity in the relationship between murre depth and krill depth becomes most apparent and at which observations of diving birds become noticeably more sparse, as $99 \%$ of the diving birds observed among krill were shallower than $80 \mathrm{~m}$.

Murres diving within krill patches accounted for approximately half of all of the diving murres observed. However, comparison of the depth of murres found outside of krill patches with the depth of other prey patches is more difficult. Squid depths could not be determined acoustically, and pollock were found in extremely small patches (e.g. $<10 \mathrm{~m}$ horizontally and vertically) that could not be associated with an individual diving murre. The depth distribution of murres not found in krill aggregations was not different than the depth distribution of pollock in the same area (Fig. 9). Outside of krill patches, murres are diving to the upper limit of pollock depths in the same area, suggesting that pollock vertical distribution is important for foraging behavior. This may be through direct means as murres feed on pollock, or through indirect means if pollock depth is an indicator of the depth of squid, which could not be measured. The second explanation seems unlikely because, al- though squid abundance significantly explained the horizontal distribution of murres at the transect scale, relatively few transects contained squid (as detected by net sampling) and these were not the same transects as those that contained pollock and thus are not included in the histogram in Fig. 9.

\section{CONCLUSIONS}

Murres were strongly correlated with their prey at a range of spatial scales during the study. At the regional scale, murre abundance was related to the combined availability and vertical accessibility of squid, krill, and pollock. There were no clear relationships between murres and any individual prey group at this scale, highlighting the importance of prey diversity to these birds. At the scale of 10 s of meters to kilometers, murres were found in distinct patches of krill disproportionate to the availability of these patches. Krill patches exploited by birds had higher krill density and were shallower than other patches, but they were similar in total krill abundance and overall size. Because overall patch size was apparently not important in the selection of krill patches by foraging murres, the relationship between murres and krill was identified at the scale of the individual krill patch which ranged in size from a few meters to a few kilometers. Analyses that search for predator-prey correlations at specific horizontal scales would have missed the observed pattern entirely. At the scale of meters, murres were highly correlated with the vertical distribution of their prey: murres were found near the minimum depth of an individual krill patch, and the depth distribution of murres matched the vertical distribution of pollock in the same area. Depth tracking of both of these prey groups as they underwent diel vertical migrations was apparent, but changes in prey characteristics that occurred throughout the day/night cycle were correlated with different uses of the sampling zones by murres on the same timescale. Observations from parallel studies at the nesting colonies and those for tagged individuals show that most murres spent their daytime hours provisioning their chicks and thus foraged in close proximity to the islands (R. Paredes, H. Renner and D. Roby pers. comm.), and our data show that, at night, adults foraged to feed themselves, consuming more invertebrate prey found in deeper waters farther from the islands, similar to the diets observed in adult birds sampled at sea during this study (N. Jones pers. comm.). All of these observations are consistent with the changes in diving murre 
habitat use and foraging tactics observed at the population rather than at the individual level. The spatial relationships observed between predator and prey in the present study, at all of these scales, were the same during both years of the study, despite large observed interannual differences in prey abundance and distribution. This suggests that the decisionmaking rules used by foraging murres did not change despite differences in prey field conditions. In both years, murres were extremely good at tracking spatial and temporal variation in their prey.

The ability of murres to successfully track the abundance, density, and accessibility of prey that occurred at depths between 10 and $100 \mathrm{~m}$ raises questions about how they gather information to exploit these resources effectively, particularly at night. Birds could be directly detecting the prey using vision or chemosensory mechanisms. However, both would likely be inefficient for deep prey, and vision would not be effective at night when foraging activity is equal to daylight foraging activity. Another possibility is that birds cue to more easily sensed variables that are also correlated with prey such as surface ocean color or physical characteristics. In this work, we examined a large number of potential cues and found a relationship between murres and surface temperature but no other variable. Given the strong co-variance between temperature and sampling zone, which also significantly affected bird distribution, it is difficult to point to this as a clear cue. Ocean color and water clarity are 2 cues that could be detected visually from the air, but no measures of these variables provided an explanation for the observed distribution of murres. Another alternative is that murres gather information from other murres. While the hypothesis that colonies function as 'information centers', where group members can learn the location of food by following successful foragers, has largely been discounted (Richner \& Heeb 1995), there have been a number of studies showing that the detection of other predators that are already exploiting a prey patch, a process known as 'local enhancement', can be an effective foraging strategy (Hinde 1956, Buckley 1997). Local enhancement occurs in another species of murre, but its importance is dependent on the predictability of prey (Davoren et al. 2003). Substantial experimental and at-sea data suggest that local enhancement works whenever feeding groups are more conspicuous than food patches (reviewed in Buckley 1997), which is likely to be the case for the deep prey observed here. The local enhancement hypothesis is supported by the prevalence of aggregation among acoustically ob- served murres. The aggregation of murres could also be the result of other processes, including behavior and fluid dynamics (O'Driscoll 1998), as well as similar search strategies (Fauchald 1999). Whatever the reason for aggregating, murres in groups were spaced in a highly regular pattern with an average of $50 \mathrm{~m}$ between individuals, suggesting that, while grouped, birds may be attempting to avoid direct competition, a common cause of uniform spacing between individuals (Sandulli \& Pinckney 1999).

The results of the present study show that fisheries acoustic techniques are an effective tool for studying diving birds and their prey. Using this technique, we were able to observe the diving depths of individual birds, assess these dives in relation to patch size, density, depth, and type of prey both day and night, and show that birds on the surface were a good proxy for foraging effort taking place in a given area. The concomitance of these data is made possible by acoustic approaches and provides new insights into the predator-prey relationship. During the breeding season, diving murres in the southeastern Bering Sea show strong selection for prey patches with specific characteristics, and the high degree of overlap between murres and their prey at a range of scales shows effective information gathering about prey by these birds.

Acknowledgements. C. Waluk, G. Kowalke, L. Whitman, N. McIntosh, S. Archer-Kraft, and A. Dauble assisted in field work. J. Condiotty of Simrad, C. Wingard, T. Cowles, B. Emmett, M. Torres, C. Miller, M. J. Zirbel, R. Letelier, and M. McManus lent equipment used in the study. D. Griffith provided information for the design of the acoustic mount. C. Waluk and M. J. Zirbel conducted preliminary data analysis. K. Shearman engaged in valuable discussions about physical oceanographic data and processes. A. Trites facilitated collaboration among research teams. G. Hunt provided constructive feedback on the study design, helpful comments on an earlier draft of the manuscript, and encouragement throughout. The captains and crews of the FV 'Frosti' and the FV 'Gold Rush' provided exceptional field support. Funding was provided by the North Pacific Research Board as part of the Bering Sea Integrated Ecosystem Research Program (BSIERP); this is NPRB Publication Number 311 and BEST-BSIERP Bering Sea Project Publication Number 27.

\section{LITERATURE CITED}

Ainley D, Ribic C, Spear L (1993) Species-habitat relationships among Antarctic seabirds: a function of physical or biological factors? Condor 95:806-816

Ainley D, Sydeman W, Norton J (1995) Upper trophic level predators indicate interannual negative and positive anomalies in the California Current food web. Mar Ecol Prog Ser 118:69-79 
Axelsen BE, Anker-Nilssen T, Fossum P, Kvamme C, Nøttestad L (2001) Pretty patterns but a simple strategy: predator- prey interactions between juvenile herring and Atlantic puffins observed with multibeam sonar. Can J Zool 79:1586-1596

Barange M (1994) Acoustic identification, classification and structure of biological patchiness on the edge of the Agulhas Bank and its relation to frontal features. S Afr J Mar Sci 14:333-347

Benoit-Bird KJ, Au WWL (2003) Prey dynamics affect foraging by a pelagic predator (Stenella longirostris) over a range of spatial and temporal scales. Behav Ecol Sociobiol 53:364-373

Benoit-Bird KJ, Würsig B, McFadden CJ (2004) Dusky dolphin (Lagenorhynchus obscurus) foraging in two different habitats: active acoustic detection of dolphins and their prey. Mar Mamm Sci 20:215-231

Benvenuti S, Bonadonna F, Dall'Antonia L, Gudmundsson G (1998) Foraging flights of breeding thick-billed murres (Uria lomvia) as revealed by bird-borne direction recorders. Auk 115:57-66

Boyd II (1996) Temporal scales of foraging in a marine predator. Ecology 77:426-434

Brierley AS, Fernandes PG (2001) Diving depths of northern gannets: acoustic observations of Sula bassana from an autonomous underwater vehicle. Auk 118: 529-534

> Buckley NJ (1997) Spatial-concentration effects and the importance of local enhancement in the evolution of colonial breeding in seabirds. Am Nat 149:1091-1112

Byrd GV, Sydeman W, Renner H, Minobe S (2008) Responses of piscivorous seabirds at the Pribilof Islands to ocean climate. Deep-Sea Res II 55:1856-1867

Coachman L (1986) Circulation, water masses, and fluxes on the southeastern Bering Sea shelf. Cont Shelf Res 5: 23-108

Coyle KO, Hunt GL Jr, Decker MB, Weingartner TJ (1992) Murre foraging, epibenthic sound scattering and tidal advection over a shoal near St. George Island, Bering Sea. Mar Ecol Prog Ser 83:1-14

> Croll D, Gaston A, Burger A, Konnoff D (1992) Foraging behavior and physiological adaptation for diving in thick-billed murres. Ecology 73:344-356

Croxall J, Everson I, Kooyman G, Ricketts C, Davis R (1985) Fur seal diving behaviour in relation to vertical distribution of krill. J Anim Ecol 54:1-8

> Davoren G, Montevecchi W, Anderson J (2003) Distributional patterns of a marine bird and its prey: habitat selection based on prey and conspecific behaviour. Mar Ecol Prog Ser 256:229-242

> De Robertis A (2010) Development and application of an empirical multifrequency method for backscatter classification. Can J Fish Aquat Sci 67:1459-1474

De Robertis A, Higginbottom I (2007) A post-processing technique to estimate the signal-to-noise ratio and remove echosounder background noise. ICES J Mar Sci 64:1282-1291

> Decker MB, Hunt GL Jr (1996) Foraging by murres (Uria spp.) at tidal fronts surrounding the Pribilof Islands, Alaska, USA. Mar Ecol Prog Ser 139:1-10

Decker MB, Hunt GL Jr, Byrd G Jr (1995) The relationships among sea-surface temperature, the abundance of juvenile walleye pollock (Theragra chalcogramma), and the reproductive performance and diets of seabirds at the Pribilof Islands. In: Beamish R (ed) Climate change and northern fish populations. National Research Council of Canada, Ottawa, p 425-437

Diner N (2001) Correction on school geometry and density: approach based on acoustic image simulation. Aquat Living Resour 14:211-222

Fauchald P (1999) Foraging in a hierarchical patch system. Am Nat 153:603-613

Foote KG, Vestnes G, Maclennan DN, Simmonds EJ (1987) Calibration of acoustic instruments for fish density estimation: a practical guide. ICES Coop Res Rep 144:1-57

Gaston A, Jones I (1998) The auks Alcidae. Oxford University Press, New York, NY

- Greene CH, Stanton TK, Wiebe PH, McClatchie S (1991) Acoustic estimates of Antarctic krill. Nature 349:110

- Grünbaum D, Veit R (2003) Black-browed albatrosses foraging on Antarctic krill: density-dependence through local enhancement? Ecology 84:3265-3275

Hickey J, Craighead F (1977) A census of seabirds on the Pribilof Islands. Ann Rep Environ Assess Alsk Cont Shelf 2:96-195

Hinde R (1956) The biological significance of the territories of birds. Ibis 98:340-369

> Hunt GL Jr (1990) The pelagic distribution of marine birds in a heterogeneous environment. Polar Res 8:43-54

Hunt GL Jr, Harrison N, Cooney R (1990) The influence of hydrographic structure and prey abundance on foraging of least auklets. Stud Avian Biol 14:7-22

> Hunt GL Jr, Coyle K, Hoffman S, Decker MB, Flint E (1996) Foraging ecology of short-tailed shearwaters near the Pribilof Islands, Bering Sea. Mar Ecol Prog Ser 141:1-11

Hunt GL Jr, Mehlum F, Russell R, Irons D, Decker MB, Becker P (1999) Physical processes, prey abundance, and the foraging ecology of seabirds. In: Adams NJ, Slotow R (eds) Proc 22nd Int Ornithol Congr, Durban. BirdLife South Africa, Johannesburg, p 2040-2056

- Kang M, Furusawa M, Miyashita K (2002) Effective and accurate use of difference in mean volume backscattering strength to identify fish and plankton. ICES J Mar Sci 59:794-804

> Kitaysky A, Hunt GL Jr, Flint E, Rubega M, Decker MB (2000) Resource allocation in breeding seabirds: responses to fluctuations in their food supply. Mar Ecol Prog Ser 206:283-296

Kokubun N, Iida K, Mukai T (2008) Distribution of murres (Uria spp.) and their prey south of St. George Island in the southeastern Bering Sea during the summers of 2003-2005. Deep-Sea Res II 55:1827-1836

Korneliussen RJ, Ona E (2002) An operational system for processing and visualizing multi-frequency acoustic data. ICES J Mar Sci 59:293-313

MacLennan DN, Simmonds EJ (1992) Fisheries acoustics. Chapman \& Hall, New York

> Mason DM, Brandt SB (1996) Effects of spatial scale and foraging efficiency on the predictions made by spatiallyexplicit models of fish growth rate potential. Environ Biol Fishes 45:283-298

Milne B, Johnston K, Forman R (1989) Scale-dependent proximity of wildlife habitat in a spatially-neutral Bayesian model. Landscape Ecol 2:101-110

> O'Driscoll R (1998) Description of spatial pattern in seabird distributions along line transects using neighbour K statistics. Mar Ecol Prog Ser 165:81-94

Obst B (1985) Densities of Antarctic seabirds at sea and the presence of the krill Euphausia superba. Auk 102: 540-549 
Piatt J (1990) The aggregative response of common murres and Atlantic puffins to schools of capelin. Stud Avian Biol 14:36-51

Richner H, Heeb P (1995) Is the information center hypothesis a flop? Adv Stud Behav 24:1-45

Rose GA, Leggett WC (1990) The importance of scale to predator-prey spatial correlations: an example of Atlantic fishes. Ecology 71:33-43

Russell RW, Hunt GL, Coyle KO, Cooney RT (1992) Foraging in a fractal environment: spatial patterns in a marine predator-prey system. Landscape Ecol 7:195-209

Sandulli R, Pinckney J (1999) Patch sizes and spatial patterns of meiobenthic copepods and benthic microalgae in sandy sediments: a microscale approach. J Sea Res 41 : 179-187

Schneider D, Piatt J (1986) Scale-dependent correlation of seabirds with schooling fish in a coastal ecosystem. Mar Ecol Prog Ser 32:237-246

Sinclair E, Vlietstra L, Johnson D, Zeppelin T and others (2008) Patterns in prey use among fur seals and seabirds in the Pribilof Islands. Deep-Sea Res II 55:1897-1918

Steele JH (1978) Spatial pattern in plankton communities. In: NATO Conference Series, Marine Sciences IV, Vol 3. Plenum Press, New York, NY, p 470

Swartzman G, Hunt G (2000) Spatial association between murres (Uria spp.), puffins (Fratercula spp.) and fish shoals near Pribilof Islands, Alaska. Mar Ecol Prog Ser 206:297-309

Takahashi A, Matsumoto K, Hunt G Jr, Shultz M and others (2008) Thick-billed murres use different diving behav-

Editorial responsibility: Andrew Brierley,

St. Andrews, UK iors in mixed and stratified waters. Deep-Sea Res II 55: 1837-1845

Tasker M, Jones P, Dixon T, Blake B (1984) Counting seabirds at sea from ships: a review of methods employed and a suggestion for a standardized approach. Auk 101: 567-577

Tiselius P, Jonsson PR, Verity PG (1993) A model evaluation of the impact of food patchiness on foraging strategy and predation risk in zooplankton. Bull Mar Sci 53:247-264

Urick RJ (1983) Principles of underwater sound. McGraw Hill, New York, NY

Veit R (1999) Behavioural responses by foraging petrels to swarms of Antarctic krill Euphausia superba. Ardea 87: 41-50

Veit R, Silverman E, Everson I (1993) Aggregation patterns of pelagic predators and their principal prey, Antarctic krill, near South Georgia. J Anim Ecol 62:551-564

Wood A, Naef Daenzer B, Prince P, Croxall J (2000) Quantifying habitat use in satellite-tracked pelagic seabirds: application of kernel estimation to albatross locations. J Avian Biol 31:278-286

Zamon JE, Greene CH, Meir E, Demer D, Hewitt R, Sexton S (1996) Acoustic characterization of the three-dimensional prey field of foraging chinstrap penguins. Mar Ecol Prog Ser 131:1-10

Zhang T, Ramakrishnon R, Livny M (1996) BIRCH: an efficient data clustering method for very large databases. In: Proc ACM SIGMOD Conf Manage Data. Association for Computing Machinery, Montreal, p 103-114

Submitted: November 22, 2010; Accepted: September 21, 2011 Proofs received from author(s): December 5, 2011 